DOI: 10.2478/linpo-2018-0011

\title{
Some general thoughts on tense and aspect in Modern Greek
}

\author{
Robert Bielecki \& Kamil Trąba \\ Institute of Linguistics, Adam Mickiewicz University in Poznań \\ robertbi@amu.edu.pl,prooffek@gmail.com
}

\begin{abstract}
Robert Bielecki \& Kamil Trąba. Some general thoughts on tense and aspect in Modern Greek. The Poznań Society for the Advancement of Arts and Sciences, PL ISSN 0079-4740, pp. 39-54

The morphological categories belonging to the semantic dimension of Tense in Modern Greek, as it is traditionally conceived, seem to be distinguished by means of non-homogeneous criteria. In this paper the temporal and aspectual meanings are treated separately. In consequence, Modern Greek has at its disposal (i) six Tenses and (ii) two Aspects. The meanings of the six Tenses are captured systemically by means of three Time-points: (i) Event Time, (ii) Reference Time and (iii) Speech Time, which are referred to each other in the order given by means of the relations of (i) previousness and (ii) simultaneity. In turn, the meanings of the two Aspects are captured by means of the notions of (i) Shortness and (ii) Longness, which are identified as the bedrock of the aspectual oppositions in Modern Greek. Other aspectual meanings such as Termination, Inchoativity, Completion, etc. are conveyed by the lexical stems of the appropriate verbs linked with the affixal markers of the two Aspects.
\end{abstract}

Keywords: Modern Greek, tense, aspect, grammaticalization, adversative sentences

\section{Introduction}

The parameters which constitute the inflectional paradigm of the Modern Greek verb are customarily, with greater or lesser deviations, referred to by means of the following

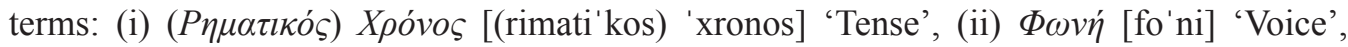

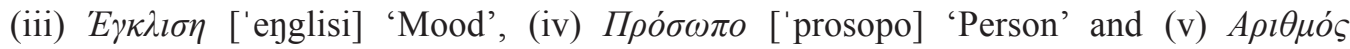
[ari $\theta$ 'mos] 'Number'. We feel justified in interpreting these as semantic dimensions.

In each of these semantic dimensions there are distinguished appropriate morphological categories. The dimension of Tense in Modern Greek comprises 8 morphological

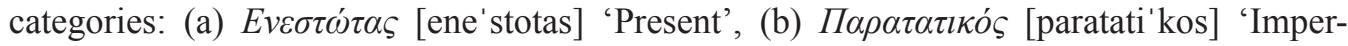

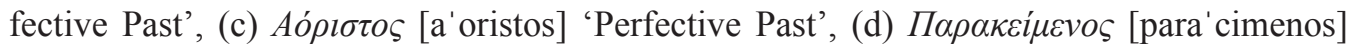

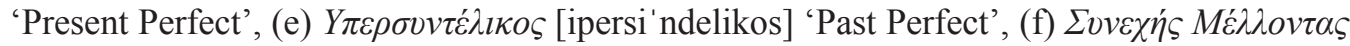

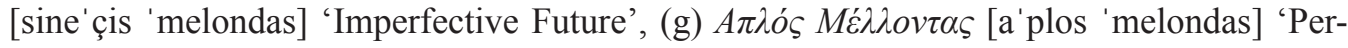

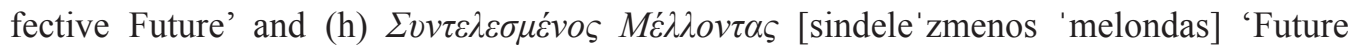




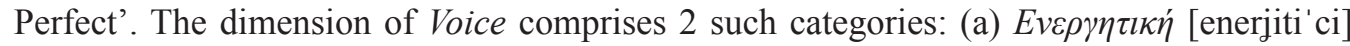

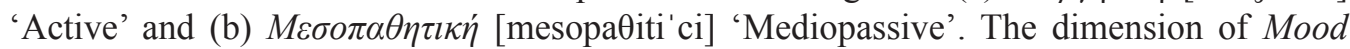

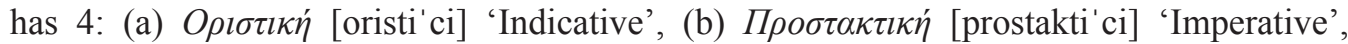

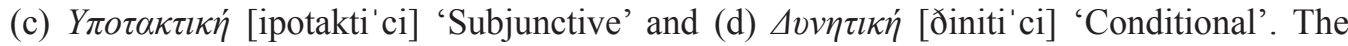

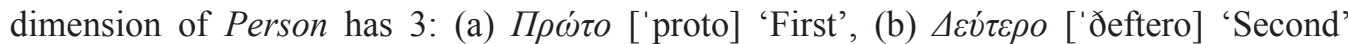
and (c) Toíto ['trito] 'Third'. Finally, the dimension of Number comprises 2 morpholog-

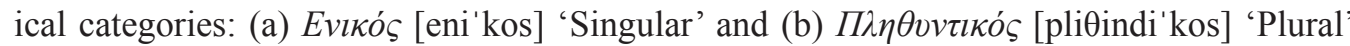
(cf. Triantafyllidis 1946: 146-147; Tzartzanos 1963: 256; Dahl 1985: 1; Paprotté 1988: 447; Hedin 1995: 233; Xydopoulos 1996: 53-54; Holton et al. 1998: 119-120; Klairis \& Mpampiniotis 2005: 449; Makropoulos 2009: 9; Tsangalidis 2013: 7; Papafilippou 2017: 895).

The markers of the morphological categories listed above, being subject to different grades of grammaticalization, acquire the form of: (i) affixes ((a) suffixes, (b) infixes, (c) circumfixes), (ii) auxiliary words and (iii) particles. In periphrastic verb forms, two

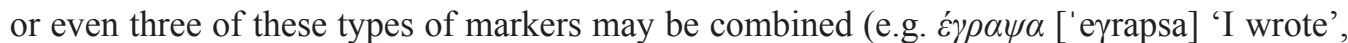

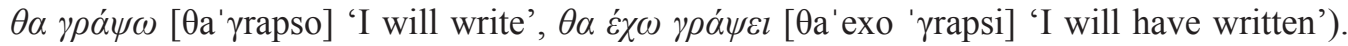

The markers of particular morphological categories characteristic of the verb in Modern Greek - as befits a typical fusional (inflectional) language - display on the one hand a high degree of allomorphy, and on the other a high degree of polysemy. For example, a form of the type $\gamma \rho \alpha \dot{\varphi} \varphi \omega$ [' $\gamma \mathrm{rafo}$ 'I write', based on today's Modern Greek paradigmatics, is morphologically analyzable as consisting of only two morphs: the lexical stem $\gamma \rho \alpha \dot{\varphi} \varphi-[\gamma \mathrm{raf}-]$ and the suffix (ending) $-\omega[-\mathrm{o}]$. Nevertheless, this verb form belongs to five morphological categories: Present Tense, Active Voice, Indicative Mood, First Person and Singular Number. If the affiliation of the verb form $\gamma \rho \alpha \dot{\varphi} \omega$ to these five categories (beside the obvious affiliation to the appropriate lexical category) is signaled by such a small number of markers, then why are these categories so meticulously kept apart? Does it not mean that in the contemporary lingual consciousness they tend to "fuse" into a single category? We would answer this question in the negative. The morphological categories of the five relevant semantic dimensions do indeed "fuse" in Modern Greek, but solely en bloc (i.e. within any verb form some category of the dimension of Tense is combined obligatorily with some category of the dimension of Voice etc.). The particular morphological categories of these dimensions do not display such fusion (cf. $\gamma \rho \alpha \dot{\varphi} \varphi \omega$

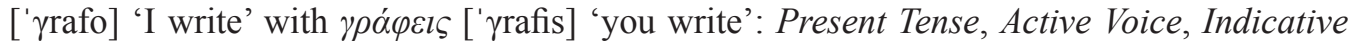
Mood, Second Person, Singular Number).

The reader may perhaps be surprised that not a single word has yet been written about meaning. This by no means implies that we are afraid to join the discussion on that topic because of its ephemerality, or because we espouse some approach to language that may be summed up as asemantic or purely morphological (cf. Bloomfield 1933: 139-157; Hockett 1958: 137-144; Antal 2005: 276-279). Quite the reverse - and indeed, we regard such an approach as illusory. As far as the morphological categories are concerned, it seems clear that those categories belonging to any semantic dimension should be bound by the relation of semantic homogeneity, i.e. they should display identity (or at least some resemblance) from the point of view of their meaning. For example, the meanings conveyed by words belonging to the morphological categories First, Second and Third 
Person refer to the communicative statuses of the participants in the communicative event (locutor, allocutive, delocutive) (cf. Bańczerowski 1977: 441-461, 1999: 59-78; Zabrocki 1980: 136-137; Bielecki 2012: 28-30).

From this standpoint, among the semantic dimensions under discussion, the dimension of Tense turns out to be the most problematic. It seems that the meanings that distinguish the different morphological categories within Tense are not semantically homogeneous. They refer simultaneously to the meanings which are known in the literature as temporal and aspectual (or even Aktionsart). This state of affairs seems to have various and multifaceted causes. One of them is certainly the unfathomable conceptualization of the notion of Time. However, in this short article we do not wish to expatiate upon a philosophical approach to Time, in spite of the obvious fact that it is unavoidably bound in some way with Tense.

What strikes one in the traditional logical construction of the semantic dimension of Tense and its subdivision into morphological categories in Modern Greek is a blindness to the fact that the possible distinguishing of different aspectual morphological categories, conveying appropriate aspectual meanings beside temporal ones, would actually change nothing in the traditional methodology of distinguishing semantic dimensions relevant to the description of the inflectional paradigms of the Modern Greek verb. We assert that the appropriate morphological categories of "pure" Tense and those of Aspect also "fuse" only en bloc. What is more, paradigmatic configurations show very clearly that we are not dealing here with some kind of imaginary deep syncretic forms (aspects fantômes).

\section{Construction of the morphological space}

A reader of Modern Greek texts, seeking speech segments (words) which convey for

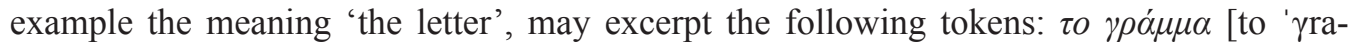

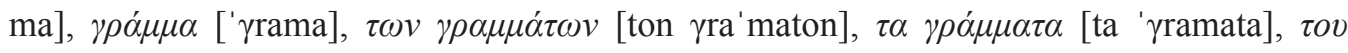

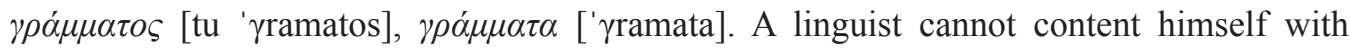
such an enumeration. His task as a scientist consists in ordering language material, in detecting regularity in the chaos which he believes to be apparent only. In the case under discussion he constructs a kind of morphological space constituted by the appropriate semantic dimensions ascribed to appropriate axes. In the case of the words just listed, the relevant morphological space seems to be relatively simple; it is constituted by two semantic dimensions (termed Number and Case) with their appropriate "values" (morphological categories). Compare Schema 1.

Broadening the scope of our investigation to include other Modern Greek nouns, for example by considering the word forms meaning 'the road', the morphological space presented in the above schema turns out to be insufficient. The "values" that need to be distinguished on the axis Case are more numerous. Let us compare Schema 2.

The superposition of Schema 2, which is more "dense" in the dimension of Case, on Schema 1 appears to produce, as if as an incidental effect, an undesired disorder. It turns out that Case $_{1}$ (Nominative) and Case ${ }_{3}$ (Accusative) differ in case of the word meaning 'the road', but are phonetically indistinguishable in case of the word meaning 'the letter'. 


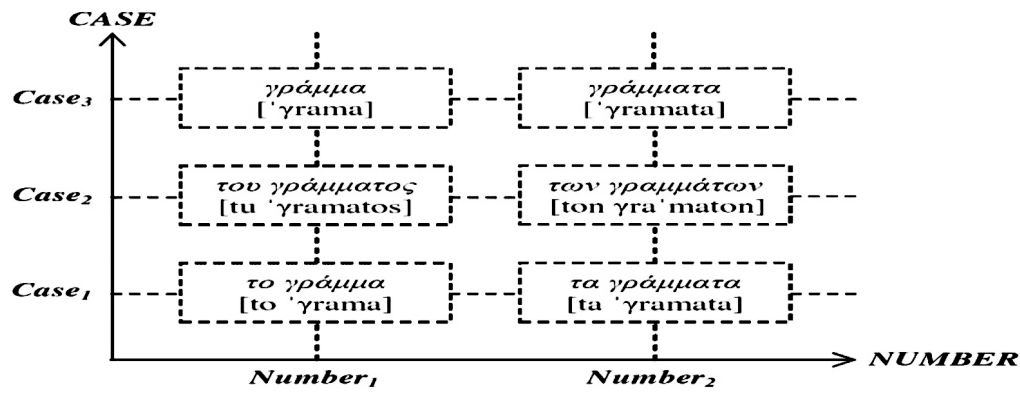

Schema 1

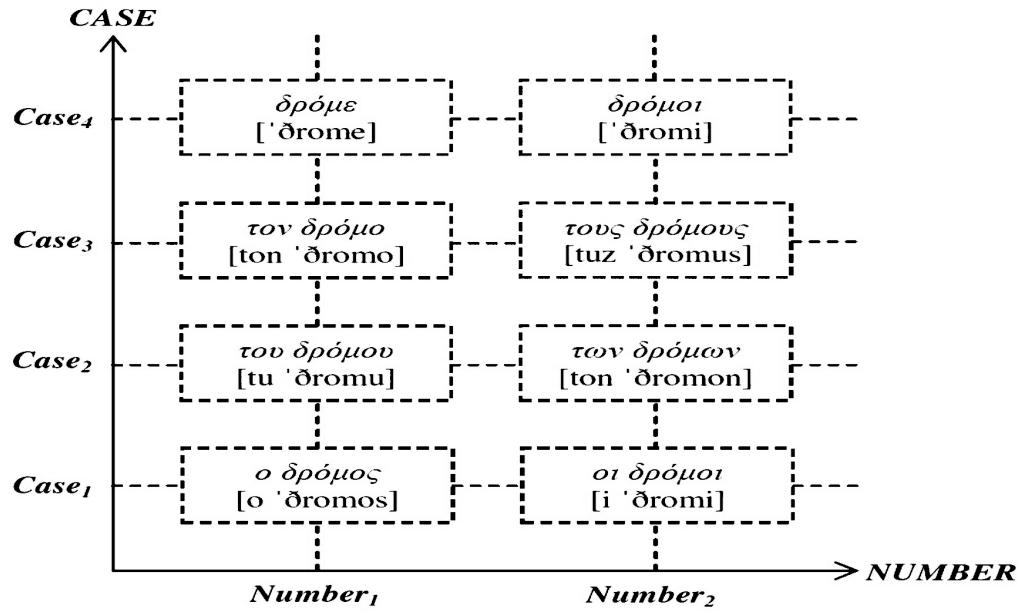

Schema 2

How to account for such an idiosyncratic fact in the light of the scientific goal of detecting regularity, if the irregularity must sooner or later emerge in the description? Such a question might be answered as follows: a scientist endeavors to detect and describe adequately as much regularity as possible at higher levels of abstraction. When one descends to lower levels of abstraction - in our case, when filling lexically the morphological space relevant to the Modern Greek noun - the obfuscating irregularities which inevitably emerge are bound only with this filling, and do not affect the relevance of the abstract schema (morphological space) itself.

\section{The temporal-aspectual morphological space}

Our everyday experience makes us conceptualize Time as a one-dimensional object, a kind of line (straight rather than circular - cf. Moser 2014: 104) on which the present Time moves forward towards the future, leaving the past behind. From this point of view the Time-line is divided into three fundamental sections: (i) past, (ii) present and (iii) 
future. These three sections are unequal in status in many senses. The past is known and irreversible. The present seems to be an ever-fleeting boundary point between the past and the future. The duration of the present time is disputable. In turn, the future is unknown and exists only in the sphere of potentiality.

The primary semantic content of the morphological categories (as lingual objects) belonging to the dimension of Tense reflects the Time. Because of communicative needs, the present moment, the Now, i.e. the moment when somebody is communicating something to somebody, is a moment which is conspicuously distinguished among all other moments. If Tense distinctions are grammaticalized in a given language, then we expect to find that they will include a distinction between Present Tense and some other Tense (cf. Greenberg 1966: 47-49). The Now is the moment around which everything revolves as far as Tense is concerned.

Analysis of the Tenses of different languages has led linguists to the conclusion that the somehow self-imposing tripartite division into (i) Past, (ii) Present and (iii) Future Tense turns out in many cases to be insufficient and inadequate. Jespersen, in his now classical work The Philosophy of Grammar, proposes to introduce even smaller divisions, concerning before- and after-relations with regard to some point in the past or future. Thus, his Tense-system comprises seven Tenses: (i) Ante-Preterite, (ii) Preterite, (iii) Post-Preterite, (iv) Present, (v) Ante-Future, (vi) Future and (vii) Post-Future (Jespersen 1965: 255-257). Reichenbach observes that, in introducing these before- and after-relations, Jespersen in fact introduces a third temporal point beside the Speech Time (S) and Event Time (E), i.e. the Reference Time (R). For example, a verb form belonging to the Ante-Preterite expresses an event which took place before some other event (expressed in the actual sentence or the actual text by some other finite verb form) which, in turn, took place before the present moment $(\mathrm{E}<\mathrm{R}<\mathrm{S})$. Reichenbach asserts that these three points (Event, Reference and Speech Time) should be considered in the analysis of all temporal forms; otherwise such Tenses as English Simple Past (e.g. I wrote) and Present Perfect (e.g. I have written) - both being absolute Tenses, in contrast to relative Tenses such as the aforementioned Ante-Preterite (Pluperfect) - remain undifferentiable in the semantic dimension of Tense. According to Reichenbach, the Event Time is never referred directly to the Speech Time. The Event Time is referred first to the Reference Time, and only the latter is referred to the Speech Time. The temporal structures of the two aforementioned English Tenses may therefore be depicted as follows: (i) Simple Past: E $=\mathrm{R}<\mathrm{S}$, (ii) Present Perfect: $\mathrm{E}<\mathrm{R}=\mathrm{S}$ (Reichenbach et al. 1967: 135).

Some languages also grammaticalize the distance between the relevant points on the Time-line. For example, in somewhat archaic written Spanish, there are two types of Ante-Preterite: (i) the remote (neutral) (e.g. habia escrito 'I had written') and (ii) the proximate (e.g. hube escrito 'I had just written') (Llorach 2000: 210-212).

Other entanglements may arise as a consequence of the gradualness of the phenomenon of grammaticalization. For example, in Swedish the construction "komma + att + infinitive' is described in the literature as "the purest expression of the future". Nevertheless, there seem still to be interwoven within it two temporal structures: (i) the historically original structure (which seems to be slowly retreating): $\mathrm{S}=$ or $<\mathrm{R}$ (komma) $<\mathrm{E}($ att + infinitive) and (ii) the new reinterpreted structure: $\mathrm{S}<\mathrm{R}($ komma $)=\mathrm{E}($ att + 
infinitive) (Sadalska 1993: 180-182; cf. also Hilpert 2006: 164-167). The Swedish sentence Jag kommer att hjälpa dig would therefore have three meanings: (i) 'I am going [now] to help you [in the future]', (ii) 'I am going [in the future] to help you [after that future moment]' and (iii) 'I will help you [in the future]'.

Our argument thus far leads us to the conclusion that as we become acquainted with the different Tense systems of world languages, we will constantly have to reinterpret our view of how many "points" must be taken into consideration if we want to reflect consistently the morphological categories within the Tense system of the language in question (cf. Bull 1968: 14-15; Vikner 1985: 95). Nevertheless, these "points" must refer, one way or another, to the present moment. Any other semantic "admixtures" found systematically in the analyzed verbal forms are irrelevant to Tense and belong to some other semantic dimension(s).

As we see it, the traditional semantic dimension of Tense in Modern Greek as presented in the Introduction, comprising eight morphological categories, is constructed so as to include such "admixtures" - in this case aspectual ones. Under the approach argued for in this article, these dimensions are explicitly distinguished from each other. The temporal-aspectual morphological space in Modern Greek therefore takes the form presented in Schema 3:

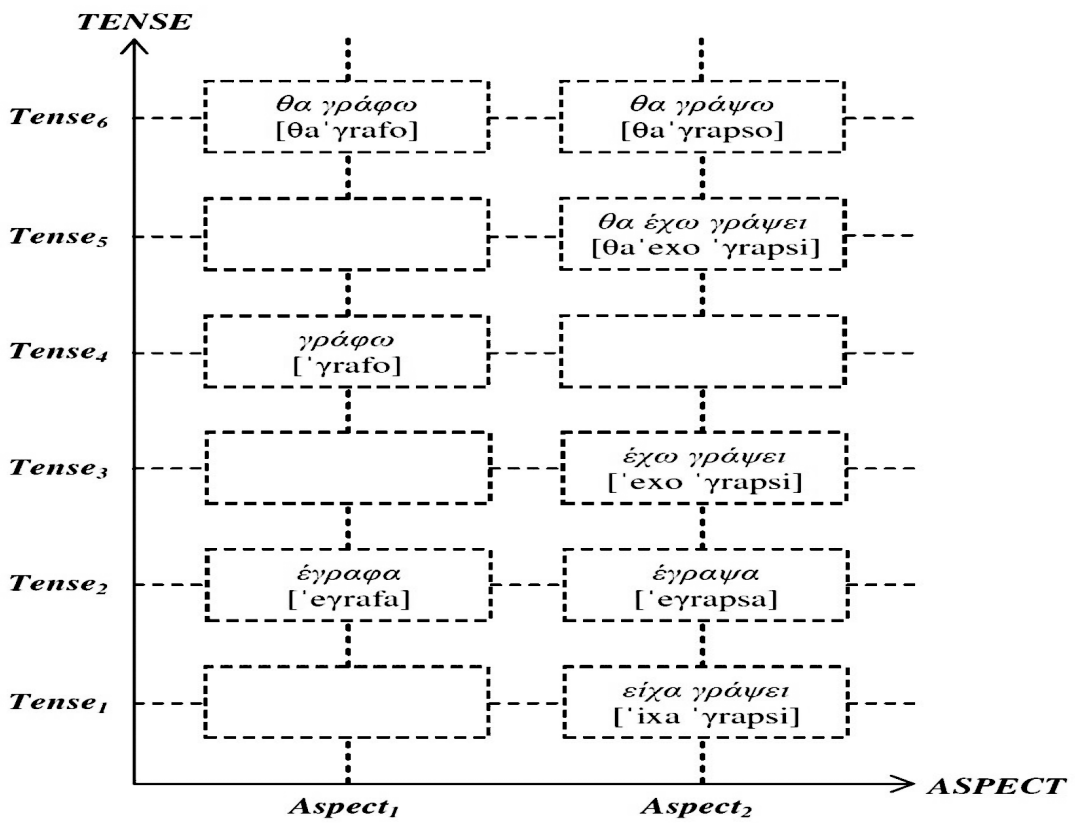

Schema 3 


\section{Tense}

The temporal meanings of the six distinguished Tenses, as morphological categories relevant to Modern Greek, can from our point of view be adequately reflected by means of three Time-points on the Time-line: (i) Event Time, (ii) Reference Time and (iii) Speech Time, in accordance with Reichenbach's approach. Let us compare Schema 4:

\begin{tabular}{|c|c|c|c|}
\hline tense & $\begin{array}{l}\text { temporal } \\
\text { meaning }\end{array}$ & example & $\begin{array}{c}\text { approximate } \\
\text { English equivalent }\end{array}$ \\
\hline Tensey & $\mathrm{E}>\mathrm{R}>\mathrm{S}$ & 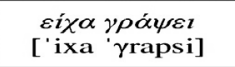 & 'I had written' \\
\hline \multirow{2}{*}{ Tense $_{2}$} & \multirow{2}{*}{$\mathrm{E}=\mathrm{R}>\mathrm{S}$} & $\begin{array}{c}\text { Éypayra } \\
\text { ['eyrapsa] }\end{array}$ & 'I wrote' \\
\hline & & 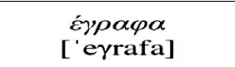 & 'I was writing' \\
\hline Tense $_{3}$ & $\mathrm{E}>\mathrm{R}=\mathrm{S}$ & 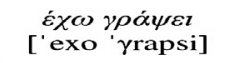 & 'I have written' \\
\hline Tense $_{4}$ & $\mathbf{E}=\mathbf{R}=\mathbf{S}$ & 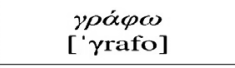 & 'I write' \\
\hline Tenses $_{5}$ & $\mathrm{~S}>\mathrm{E}>\mathrm{R}$ & 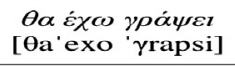 & 'I will have written' \\
\hline \multirow{2}{*}{ Tense $_{6}$} & \multirow{2}{*}{$\mathrm{S}>\mathrm{E}=\mathrm{R}$} & 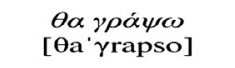 & 'I will write' \\
\hline & & $\begin{array}{l}\theta \alpha \text { ypó } \varphi \omega \\
{\left[\theta \mathbf{a}^{\prime} \gamma \mathbf{r a f o}\right]}\end{array}$ & 'I will be writing' \\
\hline
\end{tabular}

Schema 4

A verb form belonging to a certain Tense category indicates the relation of the Event Time via the Reference Time to the Speech Time in a fairly rough way. Hearing a sentence of the type I wrote a letter, we can conclude only that the event of the speaker's writing the letter took place at some moment before the Speech Time. To make this moment more specific, one has to make use of some adverbial of time or some time clause. Thus, the verb forms in question have only the potential of indicating temporal relations; the points (or sections) on the Time-line to which they refer are specified only to a certain extent. The verb forms belonging to some Tense category and the appropriate adverbials of time or time clauses are bound by the relation of semantic compatibility as regards the dimension of Tense. In other words, not all combinations of Tenses and adverbials of time or time clauses produce sensical sentences in the investigated language.

Depending on how the Reference Time is expressed, i.e. depending on whether it is expressed (i) by a sentence containing a finite verb form or (ii) just by an adverbial of time, we can distinguish two types of Tenses in Modern Greek: (i) relative and (ii) absolute. The Modern Greek language has only two relative Tenses: Tense ${ }_{1}$ and Tense ${ }_{5}$. The remaining Tenses - Tense ${ }_{2}$ Tense $_{3}$, Tense $_{4}$ and Tense ${ }_{6}$ - are absolute Tenses.

What characterizes the temporal meaning of the two relative Tenses is the fact that all of the relevant Times follow each other in some order (Tense ${ }_{1}: \mathrm{E}>\mathrm{R}>\mathrm{S}$, Tense $_{5}$ : $\mathrm{S}>\mathrm{E}>\mathrm{R}$ ). Let us take a look at some examples illustrating the use of Tense ${ }_{1}(1)$ and Tense $_{5}(2)$ : 


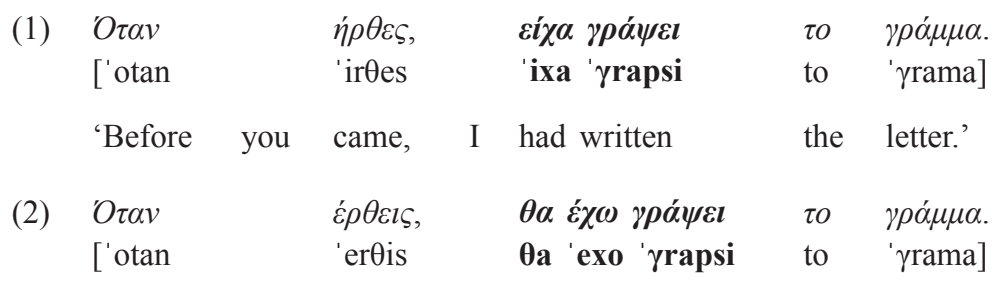

'Before you come, I will have written the letter.'

The Modern Greek absolute Tenses can be divided into three classes: (i) Tenses in which the Event Time and Reference Time are simultaneous $(\mathrm{E}=\mathrm{R})$, while the Speech Time either follows them $(\mathrm{E}=\mathrm{R}>\mathrm{S})(\mathrm{cf}$. Tense $)$ or precedes them $(\mathrm{S}>\mathrm{E}=\mathrm{R})$ (cf. Tense $)_{6}$; (ii) a Tense in which all Times are simultaneous $(\mathrm{E}=\mathrm{R}=\mathrm{S})$ (cf. Tense $\left.{ }_{4}\right)$ and (iii) a Tense in which the Event Time precedes both the Reference and Speech Time, these two being simultaneous with each other $(\mathrm{E}>\mathrm{R}=\mathrm{S})\left(\mathrm{cf}\right.$. Tense $\left.{ }_{3}\right)$. Let us take a look at some examples illustrating the use of:

(i) Tense :

\begin{tabular}{|c|c|c|}
\hline $\begin{array}{l}X \theta \varepsilon \varsigma \\
{[\mathrm{x} \theta \mathrm{es}}\end{array}$ & 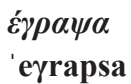 & $\begin{array}{l}\tau O \\
\text { to }\end{array}$ \\
\hline
\end{tabular}

'Yesterday I wrote the letter.'

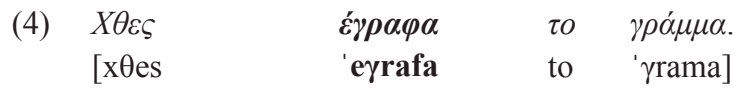

'Yesterday I was writing the letter.'

(ii) Tense

\begin{tabular}{|c|c|c|c|c|c|}
\hline (5) & $\begin{array}{l}\text { Av́pio } \\
\text { ['avrio }\end{array}$ & & 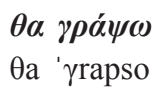 & $\begin{array}{l}\tau o \\
\text { to }\end{array}$ & $\begin{array}{l}\gamma \rho \alpha \mu \mu \alpha . \\
\text { ' } \gamma \text { rama] }\end{array}$ \\
\hline & 'Tomorrow & I & will write & the & letter.' \\
\hline & $\begin{array}{l}\text { Av́plo } \\
\text { ['avrio }\end{array}$ & & 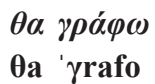 & $\begin{array}{l}\tau o \\
\text { to }\end{array}$ & ' $\mathrm{ram}$ \\
\hline
\end{tabular}

'Tomorrow I will be writing the letter.'

(iii) Tense $_{4}$ :

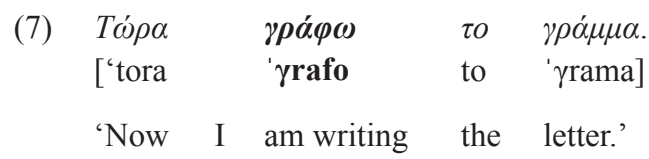


(iv) Tense ${ }_{3}$ :

(8)

\begin{tabular}{|c|c|c|}
\hline 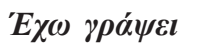 & $\dot{\eta} \delta \eta$ & $\tau o$ \\
\hline ['exo 'yrapsi & 'iði & to \\
\hline
\end{tabular}

Interestingly, the aspectual opposition seems to be direct, i.e. not involving temporal opposition, only in those Tenses in which the Event Time and the Reference Time are simultaneous and precede or follow the Speech Time (cf. Tense ${ }_{2}$ and Tense ${ }_{6}$ ).

\section{Aspect}

In the aspectological literature relating to Modern Greek it is generally agreed that there can be distinguished two types of Aspect (ówๆ ['opsi]): (i) grammatical and (ii) lexical (cf. Paprotté 1988; Moser 1994, 2009, 2014; Xydopoulos 1996; Horrocks \& Stavrou 2003a, 2003b, 2007; Kitis \& Tsangalidis 2005; Tsimpli \& Papadopoulou 2006; Sioupi 2009; Alexiadou 2010; Panitsa 2010; Tsangalidis 2014; Papafilippou 2017). In this paper we shall focus on grammatical Aspect, i.e. such Aspect whose significators are of grammatical (affixal) character.

Within grammatical Aspect there are generally distinguished two categories:

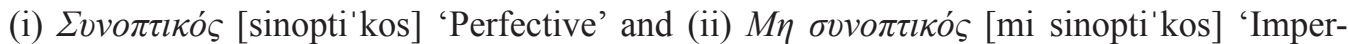
fective' (Hedin 1987; Xydopoulos \& Tsangalidis 2007; Panitsa 2010; Tsangalidis 2014).

Some of the representative attempts to capture the semantic content of both Aspects are of a descriptive and somewhat atomized nature. For instance, Horrocks \& Stavrou (2003a: 309) refer to the meaning of the Perfective Aspect as "a single, complete whole with external 'bounds' (beginnings and ends), but without specification of any internal temporal 'contour' (in Comrie's 1976 terminology) characterized in terms of properties like continuousness or progressiveness". The meaning of the Imperfective Aspect is described as "focus[ing] on part of the situation" (Alexiadou 1994: 146) or as "view[ing] the situation(s) from within" (Hedin 1995: 235). In turn, the approach of Xydopoulos \& Tsangalidis (2007: 325-335) is more systemic. They seem to assume that the relevant sentences contain information about the length of the so-called Event Time and Reference Time even without appropriate time adverbials. When the Event Time is included in (is shorter than) the Reference Time, then we are dealing with the Perfective Aspect. In the opposite case, i.e. when the Reference Time is included in (is shorter than) the Event Time, we have the Imperfective Aspect. In other words, the Perfective Aspect refers to an event whose duration does not exceed the duration of the Reference Time, whereas the Imperfective Aspect refers to an event whose duration exceeds that of the Reference Time. Newton (1979: 139) and Mackridge (1985: 113-116) attempt to grasp the semantics of both Aspects in terms of markedness, reaching the conclusion that the Perfective Aspect is the unmarked member of the opposition ("zero aspect") because its forms appear if the meaning of Durativity, Iterativity, Habituality or Progressivity is not given in the sentence or context explicitly or implicitly (cf. the arguments in: Tzevelekou 2009: 240). 
Some scholars consider the above dichotomous division of grammatical Aspect in Modern Greek to be too general, because the relevant perfective and imperfective forms display different semantic shades in different contexts. For instance, Horrocks \& Stavrou (2003a: 310-311, 2003b: 292-293) argue that the perfective verb forms may carry the

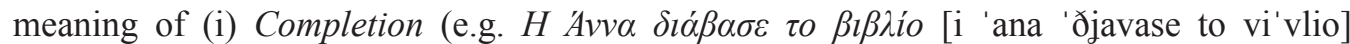

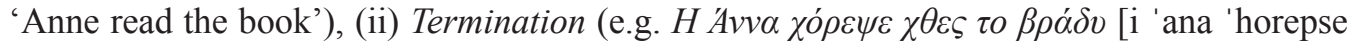

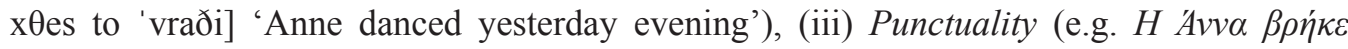
$\tau o \beta$ $\beta$ inio [i 'ana 'vrice to vi'vlio] 'Anne found the book') or (iv) Semelfactivity (e.g.

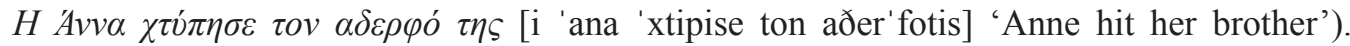
As regards the imperfective verb forms, they can be said to carry the following semantic

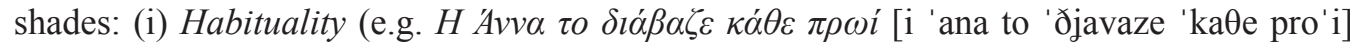

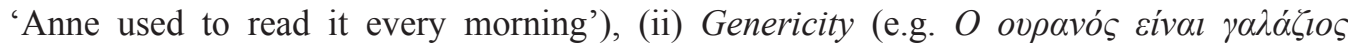

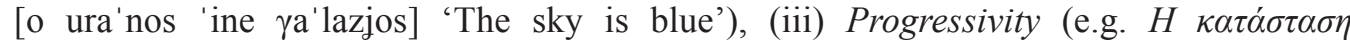
$\beta \varepsilon \lambda \tau \iota \omega v o ́ \tau \alpha v$ [i ka'tastasi veltio'notan] 'The situation was improving' and (iv) Duration

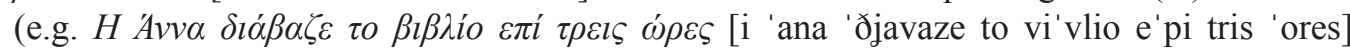
'Anne was reading the book for three hours') (Kitis \& Tsangalidis 2005: 145; Moser 2009: 66-70; Sioupi 2009: 224).

We believe that, in order to construct an appropriate picture of grammatical Aspect in Modern Greek, one should compare minimal pairs of sentences which contrast with each other on the paradigmatic plane of the language only in the dimension of Aspect. At first

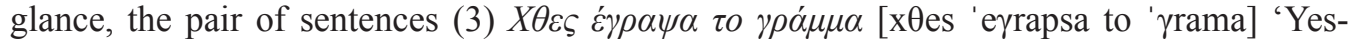

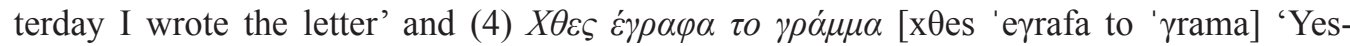
terday I was writing the letter' fulfills this condition. Nevertheless, since the relevant semantic difference between the sentences containing perfective and imperfective verb forms may be distinct from the difference between sentences (3) and (4), depending on the lexical class to which the verb belongs, the scope of our investigation should be enlarged to cover also the following representative cases:

$$
\begin{array}{lll}
X \theta \varepsilon \varsigma & & \boldsymbol{\alpha} \rho \boldsymbol{\rho} \sigma \tau \boldsymbol{\eta} \boldsymbol{\sigma} \boldsymbol{\alpha} . \\
{[\mathrm{x} \theta \mathrm{es}} & \text { a'rostisa] } \\
\text { 'Yesterday } & \text { I } & \text { got sick.' }
\end{array}
$$

(10) $\Sigma v \chi v \alpha ́$

[si'xna

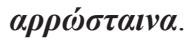

\begin{tabular}{|c|c|c|c|}
\hline \multirow[t]{2}{*}{ (11) } & $\begin{array}{l}O \\
{[\mathrm{o}}\end{array}$ & $\begin{array}{l}\pi \alpha \pi \pi o v ́ \varsigma \\
\text { pa'pus }\end{array}$ & 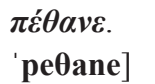 \\
\hline & 'The & grandfather & died.' \\
\hline \multirow[t]{2}{*}{ (12) } & $\begin{array}{l}O \\
{[\mathrm{o}}\end{array}$ & $\begin{array}{l}\pi \alpha \pi \pi o v \varsigma \varsigma \\
\text { pa'pus }\end{array}$ & 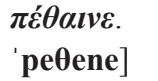 \\
\hline & 'The & grandfather & was dying.' \\
\hline
\end{tabular}

a'rostena]

'Often I I used to get sick.' 
(13)

\begin{tabular}{|c|c|c|}
\hline $\begin{array}{l}X \theta \varepsilon \varsigma \\
{[\mathrm{x} \theta \mathrm{es}}\end{array}$ & & $\begin{array}{l}\chi \delta ́ \rho \varepsilon \psi \alpha . \\
\text { 'xorepsa] }\end{array}$ \\
\hline 'Yesterday & I & danced.' \\
\hline $\begin{array}{l}X \theta \varepsilon \varsigma \\
{[\mathrm{x} \theta \mathrm{es}}\end{array}$ & & 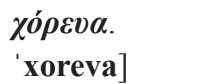 \\
\hline Yesterday & I & was dancing \\
\hline
\end{tabular}

Sentence (9) with the perfective verb form $\alpha \rho \rho \omega ́ \sigma \tau \eta \sigma \alpha$ [a'rostisa] 'I got sick' expresses Inchoativity, i.e. the beginning of the process of being sick, whereas sentence (11) with the same morphological form of the verb $\pi \dot{\varepsilon} \theta \alpha v \varepsilon$ ['pe $\theta$ ane] 'he died' expresses Completion, i.e. the resultative ending of the process of dying. Against this background, sentence (13) with the perfective verb form $\chi o ́ \rho \varepsilon \psi \alpha$ ['xorepsa] 'I danced' seems to be more similar to sentence (11) than to (9), in the sense that it expresses the event of dancing as completed. Nevertheless, as is shown by the following pair of adversative sentences ( $p$ but not $q$ ), which highlight certain relevant aspectual properties of the investigated verb forms, they cannot be considered to be aspectually indistinguishable:

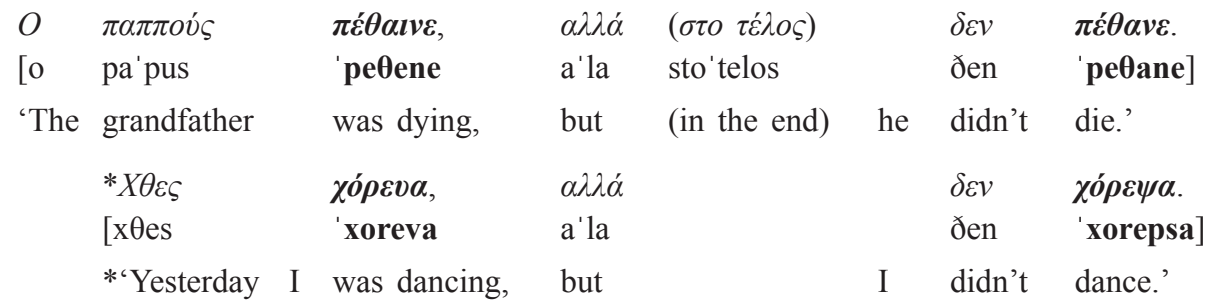

It is possible to render approximately the logic of this fragment of the Modern Greek language as follows: while dancing ( $\chi o ́ \rho \varepsilon v \alpha$ ['xoreva]) I complete 'my dancing a little' (i.e. $\chi o ́ \rho \varepsilon \psi \alpha$ ['xorepsa]) at every possible moment. This makes the adversative sentence (16) nonsensical. In turn, while dying ( $\pi \dot{\varepsilon} \theta \alpha \nu \varepsilon$ ['pe日ene]), the grandfather completes 'his dying' (i.e. $\pi \dot{\varepsilon} \theta \alpha v \varepsilon$ [pe日ane]) only at one specific moment of this process. It is possible that the grandfather was dying, but at the end he did not die at all. By taking into account this latent - as it would appear - semantic difference between the sentences (11)

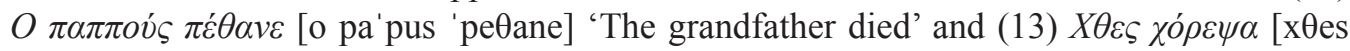
'xorepsa] 'Yesterday I danced', it is appropriate to distinguish between Completion (e.g.

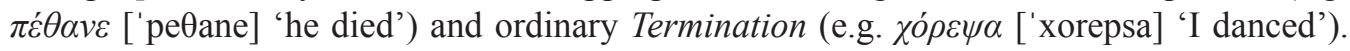

To complete the picture, let us consider the following adversative sentences:

\begin{tabular}{|c|c|c|c|c|c|c|c|c|c|c|}
\hline (17) & $\begin{array}{l}* X \theta \varepsilon \varsigma \\
{[\mathrm{x} \theta \mathrm{es}}\end{array}$ & & $\begin{array}{l}\varepsilon ́ \gamma \rho \alpha \varphi \alpha \\
\text { 'eyrafa }\end{array}$ & $\begin{array}{l}\tau o \\
\text { to }\end{array}$ & $\begin{array}{l}\gamma \rho \alpha ́ \alpha \mu \alpha, \\
\text { ' } \gamma \text { rama }\end{array}$ & $\begin{array}{l}\alpha \lambda \lambda{ }^{\prime} \\
a^{\prime} l a\end{array}$ & & $\begin{array}{l}\delta \varepsilon v \\
\text { ðen }\end{array}$ & $\begin{array}{l}\tau o \\
\text { to }\end{array}$ & $\begin{array}{l}\varepsilon ́ \gamma \rho \alpha \psi \alpha . \\
\text { 'eүrapsa] }\end{array}$ \\
\hline & *`Yesterday & I & was writing & the & letter, & but & I & didn't & write & it. \\
\hline (18) & $\begin{array}{l}X \theta \varepsilon \varsigma \\
{[\mathrm{x} \theta \mathrm{es}}\end{array}$ & & 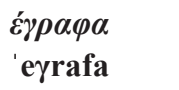 & $\begin{array}{l}\tau o \\
\text { to }\end{array}$ & $\begin{array}{l}\gamma \rho \alpha \dot{\mu} \mu \alpha, \\
\text { ' } \gamma \text { rama }\end{array}$ & $\begin{array}{l}\alpha \lambda \lambda \dot{\alpha} \\
a^{\prime} l a\end{array}$ & & $\begin{array}{l}\delta \varepsilon v \\
\text { ðen }\end{array}$ & $\begin{array}{l}\tau o \\
\text { to }\end{array}$ & $\begin{array}{l}\varepsilon ́ \gamma \rho \alpha \psi \alpha \\
\text { 'eүrapsa }\end{array}$ \\
\hline & 'Yesterday & 1 & was writing & the & letter, & but & I & didn' & writ & e all of it.' \\
\hline
\end{tabular}


The sensicality of the adversative sentence (18) indicates that the event of "my writ-

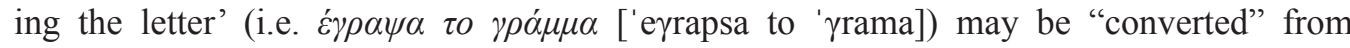
ordinarily terminative into completive by means of an auxiliary word of the type ó $\lambda o$ ['olo] 'all', which refers to the letter as the object of writing (cf. Trąba 2017).

Given this diversity of aspectual meanings of the perfective verb forms (as compared with the imperfective ones), comprising (at least) (i) Termination (convertible to Completion) ((3)-(4)), (ii) Inchoativity ((9)-(10)), (iii) Completion ((11)-(12)) and (iv) ordinary Termination ((13)-(14)), it seems justified to ask whether the morphological categories

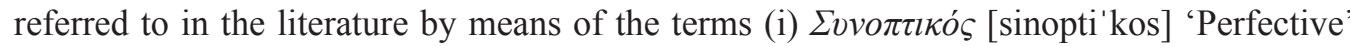

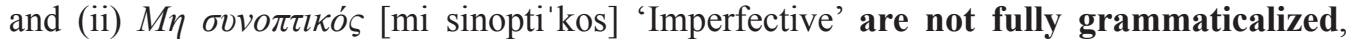
because they do not constitute semantic monoliths covering the entirety of the relevant word class (i.e. verb). In our opinion this is not the case.

Modern Greek grammaticalizes fully, in the sense just mentioned, the opposition between (i) Shortness (lack of any duration, punctuality) and (ii) Longness (duration) by means of, respectively, perfective and imperfective verb forms (i.e. the appropriate affixes). This is the bedrock of the aspectual oppositions in the language. Such meanings as Termination, Inchoativity and Completion are added by the appropriate lexical stems linked with the markers of the Perfective Aspect. The ending, beginning or completing of an action is conceptualized as lasting for a very short time (if at all). This being so, they are semantically compatible with Shortness.

In our opinion, the aforementioned semantic regularity does not seem to be invalidated by the occurrence of the following correct sentence type containing a perfective verb form and an appropriate adverbial of time expressing Durativity:

\begin{tabular}{|c|c|c|c|c|}
\hline${ }^{\prime} E \gamma \rho \alpha \psi \alpha$ & $\tau O$ & 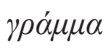 & $\sigma \varepsilon$ & $\mu i ́ \alpha$ \\
\hline ['egrapsa & to & ' $\gamma$ rama & se & 'mia \\
\hline
\end{tabular}

An adverbial of time of the type $\sigma \varepsilon \mu i \alpha \omega^{\prime} \rho \alpha$ [se 'mia 'ora] 'in an hour' does not refer to the fact reflected by the verb form $\varepsilon \gamma \rho \alpha \psi \alpha$ ['egrapsa] 'I wrote' itself, but to the

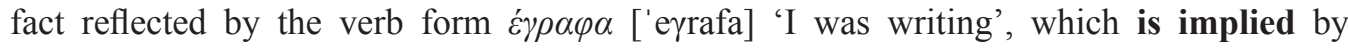
sentence (19). $\Sigma \varepsilon \mu i ́ \alpha \omega \rho \alpha$ [se 'mia 'ora] 'in an hour' is a different kind of adverbial of time than, for example, $\varepsilon \pi i$ $\mu i \alpha \omega$ ' $\rho \alpha$ [e'pi 'mia 'ora] 'for an hour', which refers directly to the fact reflected by the verb form occurring in the actual sentence containing it:

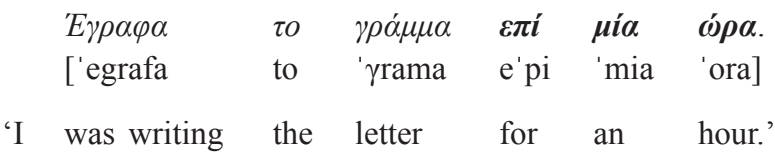




\section{Summary and conclusions}

The semantic dimensions which constitute the inflectional paradigm of the Modern Greek verb are customarily given as Tense, Voice, Mood, Person and Number. Within each of these dimensions there are distinguished appropriate morphological categories: eight Tenses, two Voices, four Moods, three Persons and two Numbers. The morphological categories relevant to the verb in Modern Greek, in spite of the scantiness of their markers in actual words - a fact which goes hand in hand with the fusional character of the language - are meticulously kept apart from each other because they are linked only en bloc, e.g. some Tense category is linked with some Voice category etc. Particular morphological categories are not subject to such linking.

The morphological categories belonging to the same semantic dimension should be bound by the relation of semantic homogeneity. From this point of view the dimension of Tense, as it is traditionally conceived in the literature, turns out to be problematic. The meanings on the grounds of which particular Tenses in Modern Greek are distinguished do not seem to be homogeneous, because they refer simultaneously to temporal and aspectual meanings. Different Tenses and Aspects, as discussed in this paper, are linked with each other en bloc also. This fact provides what appears to be additional justification for the need to distinguish a separate dimension of Aspect in opposition to "pure" Tense.

When investigating the morphology of a language, the linguist's task as a scientist consists in constructing such a morphological space (scheme) which is able to grasp as much regularity as possible at higher levels of abstraction and which is not disturbed by the (lexis-bound) irregularities that emerge when one descends to lower levels of abstraction.

The primary semantic content of the morphological categories belonging to the dimension of Tense reflects Time. In the Tense systems of ethnic languages there may indeed appear different semantic entanglements, related to the number of Time-points to be taken into account, temporal distance, gradualness of grammaticalization, etc. Nevertheless, Tenses refer ultimately to the present moment, i.e. a moment which is for communicative reasons conspicuously distinguished among all other moments. The semantic "admixtures" which do not refer one way or another to the present moment are irrelevant to Tense. The proposed morphological temporal-aspectual space for Modern Greek contains six Tenses and two Aspects.

The specificity of the Tense system of Modern Greek requires the use of three Timepoints - Event Time, Reference Time and Speech Time - which are referred to each other in the order given by means of the relations of (i) previousness ( $>$ ) and (ii) simultaneity $(=)$. Accordingly, the temporal structure of the six Modern Greek Tenses can be

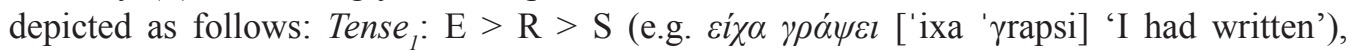

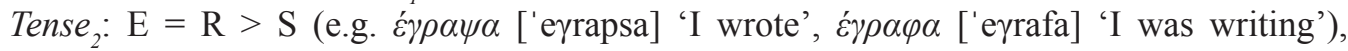

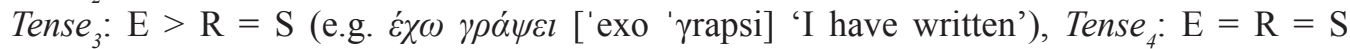

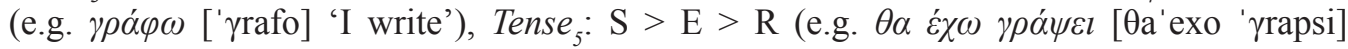

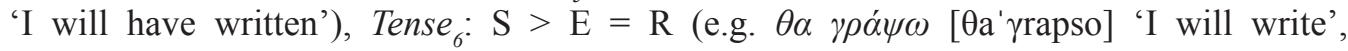
$\theta \propto \gamma \rho \alpha \dot{\alpha} \varphi \omega[\theta \mathrm{a}$ ' $\gamma \mathrm{rafo}]$ 'I will be writing').

The six Tenses may be classified into (i) relative (Tense, Tense $_{5}$ ) and (ii) absolute (Tense $_{2}$, Tense $_{3}$, Tense ${ }_{4}$, Tense $_{6}$ ) depending on whether the Reference Time is expressed by 
(i) a sentence containing a finite verb form or (ii) an adverbial of time. The absolute

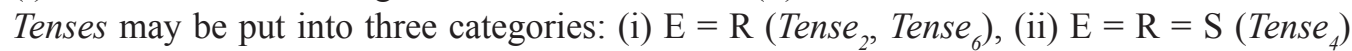
and (iii) $\mathrm{E}>\mathrm{R}=\mathrm{S}$ (Tense $_{3}$ ). Direct aspectual opposition occurs only in the case of the first category of absolute Tenses $\left(\mathrm{E}=\mathrm{R}\right.$ (Tense , Tense $\left._{6}\right)$ ).

In comparing appropriate minimal pairs of sentences, one reaches the conclusion that, depending on the lexical class to which the verb belongs, the verb forms referred to in the literature as Perfective and Imperfective convey different aspectual meanings (e.g.

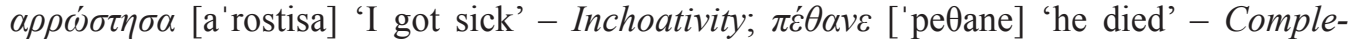
tion). This may arouse the suspicion that the categories in question are not fully grammaticalized, because they do not constitute semantic monoliths covering the entirety of the relevant word class (i.e. verb). Nevertheless, we have noted that Modern Greek grammaticalizes fully, in the sense just mentioned, the opposition between (i) Shortness and (ii) Longness by means of perfective and imperfective verb forms (i.e. the appropriate affixes). In consequence, the opposition Shortness-Longness has been identified as the bedrock of the aspectual oppositions in Modern Greek. Such meanings as Inchoativity, Completion, etc. are added only by the lexical stems linked with the markers of the appropriate Aspect.

Our goal in this paper was to present some general thoughts on Tense and Aspect in Modern Greek. The reader may evaluate whether we have achieved it. Finally, we would like to share with him or her one thought of an even more general nature. The grammatical systems of ethnic languages did not emerge ex nihilo. They are the fruit of the teleological use of the language handed down from generation to generation, at each stage striving to an astonishing degree after systemicity. The Tense-Aspect system of Modern Greek, though having its own unique features, is no exception to this rule.

\section{References}

Alexiadou, Artemis. 1994. On Aspectual and Temporal Adverbs. Themes in Greek linguistics. Papers from the first international conference on Greek linguistics, reading, September 1993, 145-152.

Alexiadou, Artemis. 2010. Nominalizations: A Probe into the Architecture of Grammar Part II: The Aspectual Properties of Nominalizations, and the Lexicon vs. Syntax Debate. Language and Linguistics Compass 4(7). 512-523.

Antal, László. 2005. A formális nyelvi elemzés. A magyar esetrendszer. Bicske: SZAK Kiadó.

Bańczerowski, Jerzy. 1997. Towards a General Theory of the Category of Person. In Ramisch, Heinrich \& Wynne, Kenneth (eds.), Language in Time and Space. Studies in Honour of Wolfgang Viereck on the Occasion of his 60th Birthday, 441-461. Stuttgart: Franz Steiner Verlag.

Bańczerowski, Jerzy. 1999. Kategoria Osoby w ujęciu Ludwika Zabrockiego. In Bańczerowski, Jerzy \& Zgółka, Tadeusz (eds.), Linguam amicabilem facere. Ludovico Zabrocki in memoriam, 59-78. Poznań: Wydawnictwo Naukowe UAM.

Bielecki, Robert. 2012. Voice and Case in Finnish in the Light of Zabrocki's Theory of Person. Lingua Posnaniensis LIV(1). 21-34.

Bloomfield, Leonard. 1933. Language. London: George Allen \& Unwin Ltd.

Bull, William E. 1968. Time, Tense, and the Verb. A Study in Theoretical and Applied Linguistics, with Particular Attention to Spanish, 1-33. Los Angeles: University of California Press.

Dahl, Östen. 1985. Tense and Aspect Systems. Oxford: Basil Blackwell.

Greenberg, Joseph. 1966. Language universals with special reference to feature hierarchies. The Hague: Mouton \& Co. 
Hedin, Eva. 1987. On the use of perfect and pluperfect in Modern Greek. Stockholm: Almqvist \& Wiksell International.

Hedin, Eva. 1995. The Tense Aspect System of Modern Greek. In Thieroff, Rolf (ed.), Tense Systems in European Languages II. Linguistische Arbeiten, 338, 233-251. Tübingen: De Gruyter.

Hilpert, Martin. 2006. A synchronic perspective on the grammaticalization of Swedish Future constructions. Nordic Journal of Linguistics 29(2). 151-172.

Hockett, Charles F. 1958. A Course in Modern Lingustics. New York: The Macmillan Company.

Holton, David \& Mackridge, Peter \& Philippaki-Warburton, Irini. 1998. Grammatiki tis ellinikis glossas (I $\rho \mu \mu-$

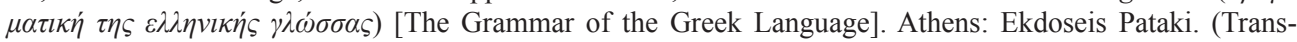
lation of Holton, David \& Mackridge, Peter \& Philippaki-Warburton, Irini 1997)

Horrocks, Geoffrey \& Stavrou, Melita. 2003a. Actions and their Results in Greek and English: The Complementarity of Morphologically Encoded (Viewpoint) Aspect and Syntactic Resultative Predication. Journal of Semantics 20. 297-327.

Horrocks, Geoffrey \& Stavrou, Melita. 2003b. O sympliromatikos charaktiras tis rimatikis opsis kai tis katigorisis tou apotelesmatos. Mia sygkritiki meleti Ellinikis - Agglikis. (O $\sigma 0 \mu \pi \lambda \eta \rho \omega \mu \alpha \tau \iota \kappa o ́ \varsigma \chi \alpha \rho \alpha \kappa \tau \eta ́ \rho \alpha \varsigma \tau \eta \varsigma$

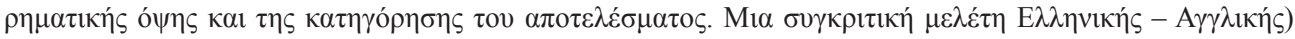
[The supplementary character of verbal aspect and the assignment of result. A Greek - English compar-

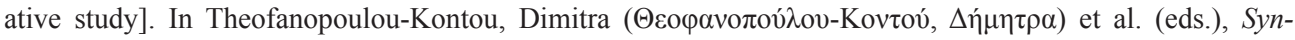

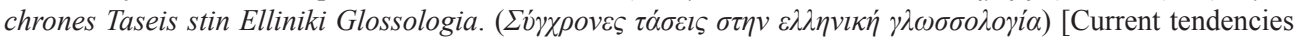
in Greek linguistics], 284-298. Athens: Ekdoseis Pataki.

Horrocks, Geoffrey \& Stavrou, Melita. 2007. Grammaticalized aspect and spatio-temporal culmination. Lingua 117. 605-644.

Jespersen, Otto. 1965. The Philosophy of Grammar. New York: The Norton Library.

Kitis, Eliza \& Tsangalidis, Anastasios. 2005. Expressivity as an option of tense-aspect in language: The case of Modern Greek imperfective past. In Marmaridou, Sophia et al. (eds.), Reviewing Linguistic Thoughts. Converging trends for the 21st century, 143-162. Berlin: Mouton de Gruyter.

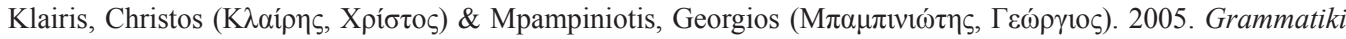

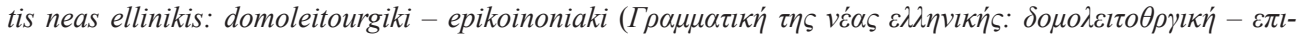
$\kappa o \iota v \omega v \iota \alpha \kappa \eta^{\prime}$ [The grammar of Modern Greek: structural - communicative]. Athens: Ellinika Grammata.

Llorach, Emilio Alarcos. 2000. Gramática de la lengua española. Madrid: Espasa.

Mackridge, Peter. 1985. The Modern Greek language: a descriptive analysis of Standard Modern Greek. Oxford: Oxford University Press.

Markopoulos, Theodore. 2009. The Future in Greek: From Ancient to Medieval. Oxford: Oxford University Press.

Moser, Amalia. 1994. Verbal aspect and Aktionsart. Athens: National and Kapodistrian University of Athens.

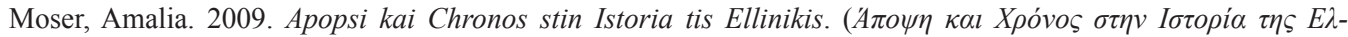
$\left.\lambda \eta \nu \imath \eta_{s}\right)$ [Aspect and Tense in the History of Greek]. Athens: Myron Romanos E.P.E.

Moser, Amalia. 2014. Aspect and Aktionsart - A Study on the Nature of Grammatical Category. In Lavidas, Nikolaos et al. (eds.), Major Trends in Theoretical and Applied Linguistics 1, 99-120. London: Versita Ltd.

Newton, Brian. 1979. Scenarios, Modality, and Verbal Aspect in Modern Greek. Language 55(1). 139-167.

Panitsa, Georgia. 2010. Aspects of Aspect: The acquisition of viewpoint and situation aspect in Modern Greek. (Doctoral dissertation.) http://discovery.ucl.ac.uk/118204/1/118204.pdf. (Accessed 2017-11-19.)

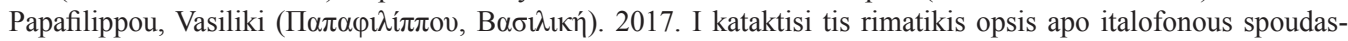

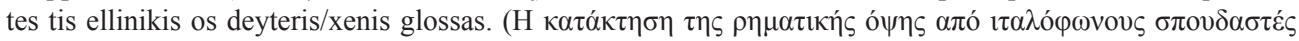
$\tau \eta \varsigma \varepsilon \lambda \lambda \eta v i \kappa \eta ́ \varsigma \varsigma \varsigma \delta \varepsilon v ́ \tau \varepsilon \rho \eta \varsigma / \xi \dot{\varepsilon} v \eta \varsigma \gamma \lambda \omega \sigma \sigma \alpha \varsigma$ ) [The mastery of grammatical aspect by italophone students of Greek as a second or foreign language]. Proceedings of the 37th Annual Meeting of the Department of Linguistics of the Aristotle University of Thessaloniki, 891-907. http://ins.web.auth.gr/images/MEG_PLIRI/ MEG_37_891_908.pdf. (Accessed 2018-02-01.)

Paprotté, Wolf. 1988. A Discourse Perspective on Tense and Aspect in Standard Modern Greek and English. In Rudzka-Ostyn (ed.), Topics in Cognitive Linguistics, 447-505. Amsterdam: John Benjamins Publishing Co.

Reichenbach, Hans et al. 1967. Logika i język. Studia z semiotyki logicznej. Warsaw: Państwowe Wydawnictwo Naukowe. [translated by Jerzy Pelc]

Sadalska, Genowefa. 1993. Tidskategorin i svenskan. Cracow: Uniwersytet Jagielloński. 


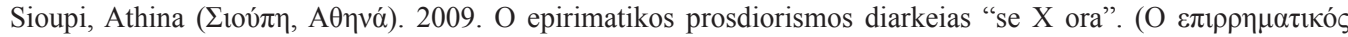

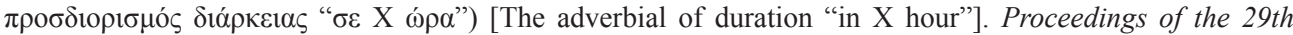
Annual Meeting of the Department of Linguistics of the Aristotle University of Thessaloniki, 221-235.

Trąba, Kamil. 2017. The morphological category of aspect and its insufficiency in marking completion in Modern Greek. Paper presented at the conference of International Conference on Greek Linguistics, London, 7-9th September 2017. https://www.academia.edu/36868737/The_morphological_category_of_aspect_ and_its_insufficiency_in_marking_completion_in_Modern_Greek. (Accessed 2018-09-07.)

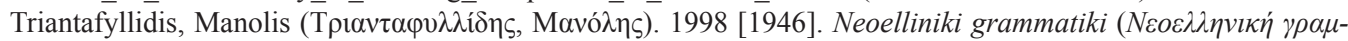

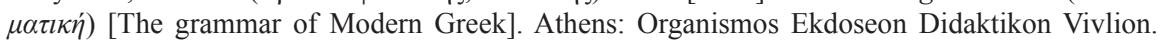

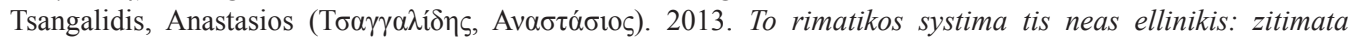

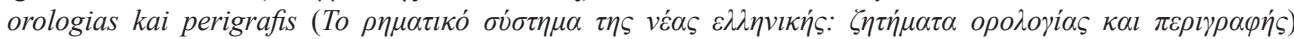
[The verb system of Modern Greek: issues of terminology and description]. http://elearning.greek-language. gr/pluginfile.php/1134/mod resource/content/5/rimaorologia.pdf. (Accessed 2018-02-01.)

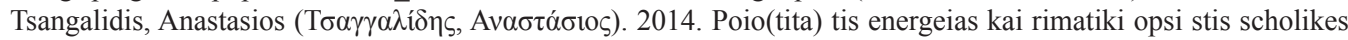

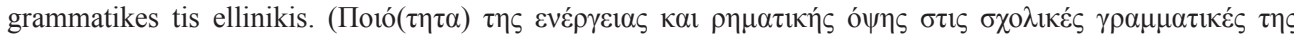
$\varepsilon \lambda \lambda \eta v i \kappa \eta ́ s)$ [Type (quality) of action and verbal aspect in school grammars of Greek]. Proceedings of the 34th Annual Meeting of the Department of Linguistics of the Aristotle University of Thessaloniki, 431-443.

Tsimpli, Ianthi Maria \& Papadopoulou, Despina. 2006. Aspect and argument realization: A study on antecedentless null objects in Greek. Lingua 116. 1595-1615.

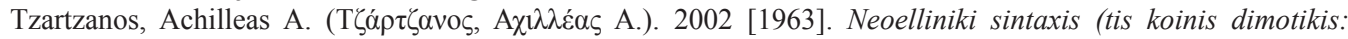

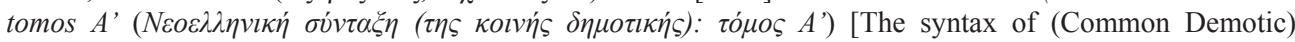
Modern Greek: vol. 1]. 2nd edn. Athens: Ekdotikos Oikos Adelfon Kyriakidi A.E.

Tzevelekou, Maria. 2009. Oi opseis ton katastaseon. (Oı ó $\psi \varepsilon 1 \varsigma \tau \omega v \kappa \alpha \tau \alpha \sigma \tau \alpha \dot{\sigma} \sigma \varepsilon \omega v)$ [The aspects of states]. Proceedings of the 29th Annual Meeting of the Department of Linguistics of the Aristotle University of Thessaloniki, 236-247.

Vikner, Sten. 1985. Reichenbach Revised: One, Two or Three Temporal Relations? Acta Linguistica Hafniensia 19(2). 81-98.

Xydopoulos, Georgios I. 1996. Tense, aspect, and adverbials in Modern Greek. London: University College London. (Doctoral dissertation.)

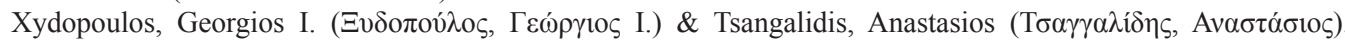

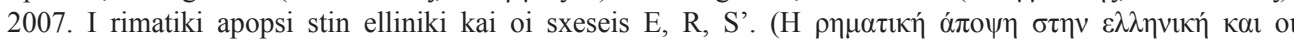
$\sigma \chi \varepsilon \dot{\sigma \varepsilon \varepsilon \varsigma} \mathrm{E}, \mathrm{R}, \mathrm{S})$ [Verbal aspect in Greek and E, R, S relations]. Proceedings of the 27th Annual Meeting of the Department of Linguistics of the Aristotle University of Thessaloniki, 263-276.

Zabrocki, Ludwik. 1980. U podstaw struktury i rozwoju języka. Warsaw, Poznań: Państwowe Wydawnictwo Naukowe. 